University of Nebraska - Lincoln

DigitalCommons@University of Nebraska - Lincoln

Faculty Papers and Publications in Animal

Science

Animal Science Department

2009

\title{
Effect of Sorting and Optaflexx Supplementation on Feedlot Performance and Profitability of Long Yearling Steers
}

\author{
W. A. Griffin \\ University of Nebraska-Lincoln \\ T. J. Klopfenstein \\ University of Nebraska-Lincoln, tklopfenstein1@unl.edu \\ G. E. Erickson \\ University of Nebraska-Lincoln, gerickson4@unl.edu \\ D. M. Feuz \\ University of Nebraska-Lincoln \\ K. J. Vander Pol \\ University of Nebraska-Lincoln \\ See next page for additional authors
}

Follow this and additional works at: https://digitalcommons.unl.edu/animalscifacpub

Part of the Animal Sciences Commons

Griffin, W. A.; Klopfenstein, T. J.; Erickson, G. E.; Feuz, D. M.; Vander Pol, K. J.; and Greenquist, Matthew A., "Effect of Sorting and Optaflexx Supplementation on Feedlot Performance and Profitability of Long Yearling Steers" (2009). Faculty Papers and Publications in Animal Science. 763.

https://digitalcommons.unl.edu/animalscifacpub/763

This Article is brought to you for free and open access by the Animal Science Department at DigitalCommons@University of Nebraska - Lincoln. It has been accepted for inclusion in Faculty Papers and Publications in Animal Science by an authorized administrator of DigitalCommons@University of Nebraska - Lincoln. 


\section{Authors}

W. A. Griffin, T. J. Klopfenstein, G. E. Erickson, D. M. Feuz, K. J. Vander Pol, and Matthew A. Greenquist 

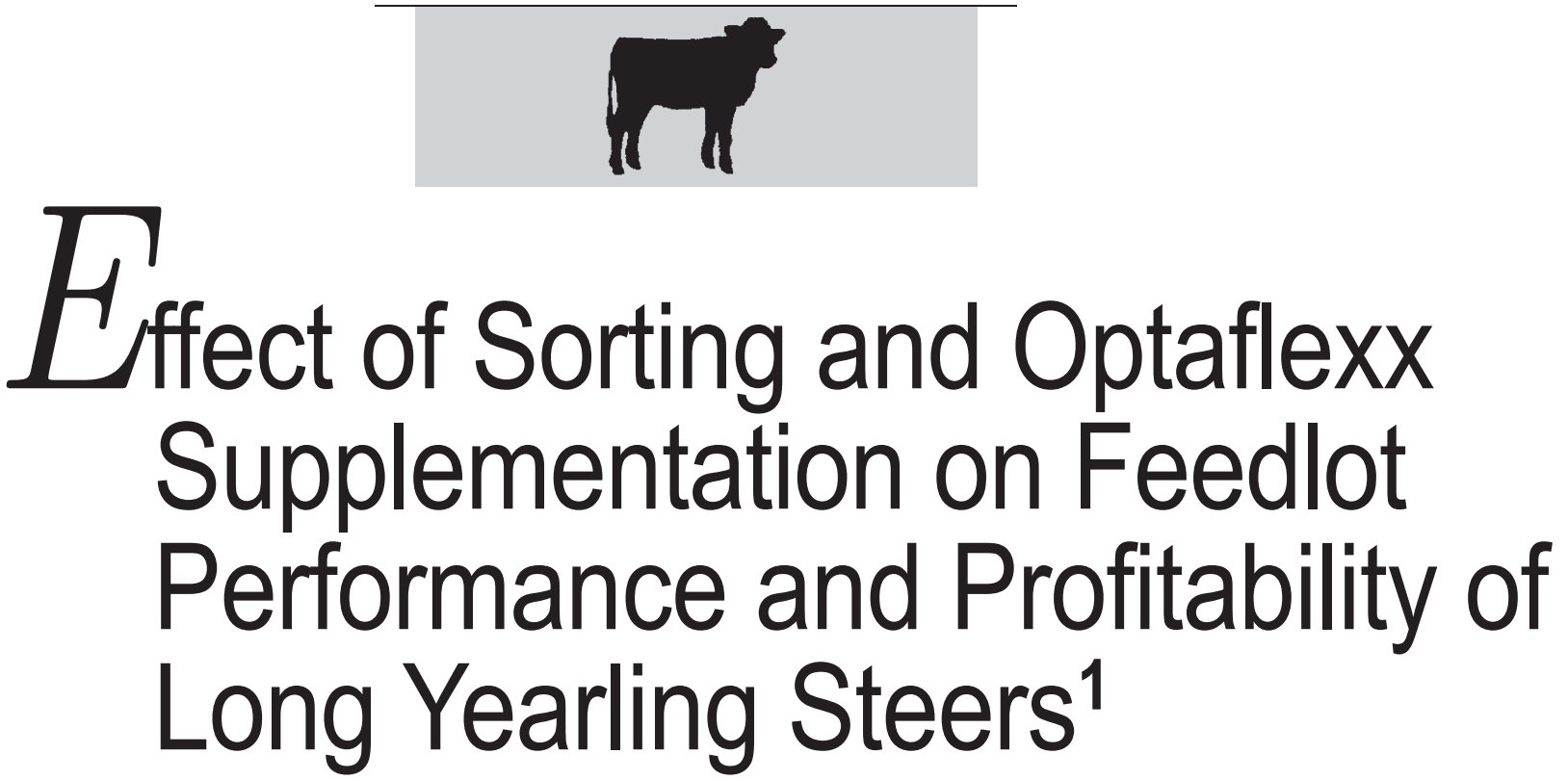

\section{W. A. Griffin, PAS, T. J. Klopfenstein, ${ }^{2}$ G. E. Erickson, PAS, D. M. Feuz, ${ }^{3}$ K. J. Vander Pol, ${ }^{4}$ and}

M. A. Greenquist ${ }^{5}$

Department of Animal Science, University of Nebraska, Lincoln 68583

\begin{abstract}
A 2-yr study was conducted using 200 long yearling steers $/ y r(436 \pm 30 \mathrm{~kg})$ to determine the effect on performance and economics of sorting by $B W$ at feedlot entry and feeding $200 \mathrm{mg} /$ steer of Optaflexx (OPT) daily for the last $28 d$. At feedlot entry, steers were allotted into 1 of 4 treatments in a $2 \times 2$ factorial arrangement: sorted or unsorted with or without OPT. Sorted steers were placed into 1 of 3 groups - 1) heavy steers (32\%; $468 \mathrm{~kg})$, 2) medium steers (44\%; $432 \mathrm{~kg}$ ), or 3) light steers (24\%; $399 \mathrm{~kg}$ ) - and were fed for 97, 118, or $132 d$, respectively. Initial $B W$ for unsorted steers averaged $436 \mathrm{~kg}$ and steers were fed 111 $d$. There were no sorted $\times$ OPT interac-
\end{abstract}

\footnotetext{
${ }^{1}$ A contribution of the University of Nebraska Agricultural Research Division, supported in part by funds provided through the Hatch Act.

${ }^{2}$ Corresponding author: tklopfenstein1@unl. edu

${ }^{3}$ Current address: Utah State University, 3530 Old Main Hill, Logan, UT 84322.

${ }^{4}$ Current address: Koers-Turgeon Consulting Services, 1373 Golden Hills Lane, Peidmont, OK 73078.

${ }^{5}$ Current address: Cargill Animal Nutrition, 3811 X Street, Lincoln, NE 68503.
}

tions $(P>0.10)$ and feeding OPT did not affect steer performance $(P>0.10)$. Sorted steers were fed more days than unsorted steers (114 vs. 111) and were not statistically different in final $B W$ (645 vs. $640 \mathrm{~kg} ; P=0.15)$ or hot carcass weight (406 vs. $403 \mathrm{~kg} ; P=0.14$ ). Sorting increased $L M$ area $(P<0.01)$, fat thickness $(P=0.02)$, and percentage of $Y G$ \& carcasses or higher $(P<0.01)$. From this study, we concluded there were no benefits to sorting long yearling steers by initial $B W$ or feeding OPT to long yearling steers for the last $28 d$ of the feeding period.

Key words: Optaflexx, sorting, long yearling

\section{INTRODUCTION}

Production of overweight carcasses is a concern with long yearling production systems (cattle that enter the feedlot at 17 mo after an extended grazing period; Griffin et al., 2007). The cattle population is diverse in BW and body type (Dolezal et al., 1993). Early identification of animals that produce overweight carcasses is important to profitability because $\mathrm{BW}$ is a major determinant of animal value (Owens et al., 1993; Shain et al., 2005). Increasing days fed can increase discounts from YG 4 and heavy carcasses; however, economic losses can be recovered because of increased QG and the benefits of additional BW (Feuz, 2002).

Sorting may be used to reduce BW variation and overweight carcasses. MacDonald et al. (2002) found that initial feedlot BW of long yearlings was a good predictor of final BW $\left(\mathrm{r}^{2}=0.83\right)$. Folmer et al. (2008) used long yearlings in a 3 -way sorting system to decrease overweight carcasses and increase uniformity. In a report by Folmer et al. (2008), sorting reduced overweight carcasses and increased average carcass weights because removing heavier cattle allowed lighter cattle to be fed longer. Additionally, Folmer et al. (2008) concluded that sorting reduced final BW variation. However, profitability was not affected. Therefore, sorting long yearlings by BW at feedlot entry could reduce overweight carcasses and prevent overweight discounts.

Feeding $\beta$-adrenergic agonists increases muscle accretion and decreases fat accretion (Mersmann, 1998). Optaflexx (Elanco Animal Health, 
Greenfield, IN), the trade name for ractopamine hydrochloride, is a $\beta-1$ adrenergic agonist. Optaflexx has been shown to improve G:F and increase BW without affecting QG when fed for the last 28 to $42 \mathrm{~d}$ at a rate of 100 to $300 \mathrm{mg} /$ steer daily (Schroeder et al., 2003; Crawford et al., 2006). Using a product that increases BW in long yearling systems, where production of overweight carcasses is a concern, could show additional sorting benefits.

Therefore, the objectives of this study were 1) to compare the performance and economics of long yearling steers sorted by initial BW with an unsorted control, 2) to determine the effects of feeding $200 \mathrm{mg}$ Optaflexx/ steer daily for the last $28 \mathrm{~d}$ to long yearling steers, and 3) to determine their interaction.

\section{MATERIALS AND METHODS}

\section{Wintering Period}

Two hundred medium-framed English-cross steers $(\mathrm{BW}=235 \pm 21 \mathrm{~kg})$ were used in each year of a 2-yr study conducted from December 2003 to January 2006. Steers were purchased in the fall and were allowed a 28-d adaptation period before the beginning of the trial. Steers designated to this trial were from multiple sale-barn sources (2 loads from 2 sale barns in yr 1 , and 3 loads from 3 sale barns in yr 2) to simulate a production system in which all steers from a calf crop are developed into long yearlings. Because lighter steers at weaning are the ones that enter the University of Nebraska long yearling system, steers purchased for the long yearling system were lighter cattle sold at the sale barns on the respective sale dates. Steers in yr 1 had a BW of 226 $\mathrm{kg}(\mathrm{SD}=18)$ and steers in yr 2 had a $\mathrm{BW}$ of $234 \mathrm{~kg}(\mathrm{SD}=22)$. Steers were managed as one group in the winter and allowed to graze cornstalk residue from December 2, 2003, until April 20, 2004, in yr 1 and from November 11, 2004, until April 20, 2005, in yr 2. Steers were supplemented daily with $2.27 \mathrm{~kg} /$ steer of wet corn gluten feed
(WCGF; DM basis) for the entire wintering period to achieve a BW gain of $0.68 \mathrm{~kg} / \mathrm{d}$ or better (Jordon, 2000).

Summer Period. On April 20 of each year, cattle were implanted with Revelor-G (Intervet Inc., Millsboro, DE) and placed on smooth brome pastures near Mead, Nebraska, until May 20. On May 20, steers were vaccinated for pinkeye, branded, and transported to native warm-season pastures near Rose, Nebraska. Cattle were removed from pasture on September 8 in yr 1 and on September 13 in yr 2. While on grass, steers were managed as one group.

Finishing Period. Steers were adapted to the final finishing diet in $21 \mathrm{~d}$, using 4 grain adaptation diets containing $45,35,25$, and $15 \%$ roughage and fed for $3,5,6$, and $7 \mathrm{~d}$, respectively. The final finishing diet contained (DM basis) 48\% high-moisture corn, 40\% WCGF, 7\% alfalfa hay, and $5 \%$ supplement, and contained a minimum of (DM basis) $12.00 \% \mathrm{CP}, 0.70 \% \mathrm{Ca}, 0.35 \% \mathrm{P}$, $0.60 \% \mathrm{~K}$, and $33 \mathrm{~g} /$ tonne monensin (Elanco Animal Health), and $11 \mathrm{~g} /$ tonne tylosin (Elanco Animal Health). Additionally, half the cattle were supplemented with Optaflexx for the last $28 \mathrm{~d}$ of the feeding period at a daily rate of $200 \mathrm{mg} / \mathrm{steer}$.

Initial and final BW for all periods of the growing system were based on 2-d consecutive BW following $5 \mathrm{~d}$ of limit feeding a diet of $50 \%$ alfalfa and 50\% WCGF (DM basis). Twoday BW were used to help reduce the daily variation in BW of the animal (Stock et al., 1983). At feedlot entry, all steers were implanted with Synovex-Choice (Fort Dodge Animal Health, Overland Park, KS), weighed, and sorted into pens. Final BW at the end of the finishing period was based on hot carcass weight (HCW), assuming a constant dressing percentage of $63 \%$. Steers were slaughtered at the same commercial abattoir. On the day of slaughter, HCW and liver scores were collected. After a 48-h chill, 12th-rib fat thickness (FT), LM area, calculated YG, and USDA QG were collected. Yield grade was calculated as $2.5+(6.35 \times \mathrm{FT}, \mathrm{cm})+(0.0017$ $\times \mathrm{HCW}, \mathrm{kg})+(0.2 \times \mathrm{KPH}, \%)-$ $\left(2.06 \times \mathrm{LM}\right.$ area, $\left.\mathrm{cm}^{2}\right)($ Boggs and Merkel, 1993).

Sorting. In both years after the summer grazing period, steers were weighed, stratified by BW, and allotted into groups of 25 , with each group having similar average BW. Steers were then sorted into 1 of 4 treatment groups. Treatments were as follows: 1) sorted without Optaflexx supplementation, 2) sorted with Optaflexx supplementation, 3) unsorted without Optaflexx supplementation, and 4) unsorted with Optaflexx supplementation. Steers that were sorted were placed into 1 of 3 sort groups: the heavy sort $(32 \%$ of cattle, $\mathrm{BW}=468$ $\pm 19 \mathrm{~kg}$ ) contained 8 steers per pen, the medium sort ( $44 \%$ of cattle, BW $=432 \pm 14 \mathrm{~kg}$ ) contained 11 steers per pen, and the light sort (24\% of cattle, $\mathrm{BW}=399 \pm 14 \mathrm{~kg}$ ) contained 6 steers per pen. Steers in the unsorted control $(\mathrm{BW}=436 \pm 31 \mathrm{~kg})$ were fed for an average of $111 \mathrm{~d}$ in a pen containing 25 steers. Steers in the heavy, medium, and light groups were fed for an average of 96, 118, and $132 \mathrm{~d}$, respectively. After steers were sorted into treatment groups, they were randomly assigned to a feedlot pen. Additionally, pens were all in a similar location within the feedlot.

Steers in this study were determined as ready for slaughter when steers in the control group were estimated to have 1.14 to $1.27 \mathrm{~cm}$ of rib FT and had achieved a Choice QG. Estimation of FT for cattle in this study was determined from previous research in which similar cattle were fed (MacDonald et al., 2006; Griffin et al., 2007; Folmer et al., 2008). Days fed for sorted steers was determined by using estimations similar to those for the control steers but by factoring in the number of days at which sorted cattle would begin to produce overweight carcasses (Folmer et al., 2008). Similar to the report by Folmer et al. (2008), it was determined that steers sorted into the heavy group needed to be marketed 2 wk before control steers. Because heavy steers were removed from the sorted steer 
group, medium and light steers in the sorted group could be fed for more days. Feeding for more days increases BW gain without increasing the risk of producing overweight carcass because heavier steers in the pen are removed. Removing the heavy steers from the sorted group allowed medium and light steers to be marketed 1 and 3 wk after the control steers, respectively. For data analysis, steer performance from the sort groups was combined and analyzed as a pen containing 25 steers. Pen space and available bunk space per animal were kept constant at $21 \mathrm{~m}^{2}$ and $46 \mathrm{~cm}$, respectively.

Variation Analysis. Folmer et al. (2008) showed that sorting improved carcass weight uniformity. Therefore, it was hypothesized that sorting and marketing steers accordingly would increase carcass weight uniformity. To determine the effects of sorting on carcass uniformity, the SD for initial $\mathrm{BW}$, final BW, $\mathrm{HCW}$, marbling score, YG, FT, LM area, and ADG were analyzed within pen (group). Analysis was performed using a $\log _{10}$ transformation of the SD of the means of the experimental units. $\log _{10}$ transformations are used to make SD proportional to the mean of the variable (Kuehl, 2000).

\section{Wintering Period Economics.}

Costs of animals and feed ingredients were calculated using 7-yr average pricing for the month that cattle were bought and the months that feed ingredients were fed. For steer initial cost, average BW of a replicate was multiplied by the USDA Nebraska auction market 1998 to 2004 average December calf price $(\$ 102.97 / 45$ $\mathrm{kg}$ ) for 227- to $272-\mathrm{kg}$ feeder calves (Feuz, 2004). Steers were assessed $\$ 8.33 /$ steer for health and processing costs during the winter period. Simple interest was assessed on initial steer cost and health over the entire ownership period. Interest was charged using the prime interest rate plus $1 \%$ $(7.6 \%)$ for all costs.

The cost of corn residue was determined at a daily rate of $\$ 0.32 /$ steer while steers grazed cornstalk residue. This cost included $\$ 0.12$ /steer for the rent of cornstalk residue and $\$ 0.20$ / steer of yardage. The yardage cost included the cost of fencing stalk fields and the cost of labor to deliver WCGF and water to the cattle.

Steers were supplemented daily with $2.27 \mathrm{~kg} /$ steer (DM basis) of WCGF for the entire winter period at a cost of $\$ 92.62 /$ metric ton (DM basis). This price was equal to $95 \%$ of the price of corn (Erickson et al., 2005) when corn was $\$ 0.084 / \mathrm{kg}$ (as-is basis). Interest was charged on half the WCGF for the winter period. The total winter cost was calculated using a $1.5 \%$ death loss.

\section{Summer Period Economics.}

Summer grazing cost was determined using the 7-yr average animal unit month (AUM) value of $\$ 23.29$ for native range (Johnson and Raymond, 1993-2005). An AUM is defined as the amount of forage an animal unit requires in $30 \mathrm{~d}$ (Meyer et al., 2008). In work by Kleiber (1975), an animal unit was defined as $\mathrm{X}=(\mathrm{M} / 450)^{0.75}$, where $\mathrm{X}$ is animal units and $\mathrm{M}$ is the BW of the animal in kilograms. This procedure described by Kleiber (1975) was used to determine animal unit equivalents of the steers used in this study. For this calculation, the initial and final grazing BW were averaged $(\mathrm{M})$. To determine the total AUM used during summer grazing, the number of days was divided by 30 and multiplied by the animal unit equivalent. The AUM usage was then multiplied by the AUM value to determine the cost of native range during summer grazing.

Cattle were assessed $\$ 8.33$ for a summer health cost, and a death loss of $0.5 \%$ was assumed. Interest was charged for the cost of grazing by using the prime interest rate plus $1 \%$ for the cost of the AUM and the health cost.

\section{Finishing Period Economics.} The finishing cost included feed (\$109.48/metric ton; DM basis) and yardage. Cattle fed Optaflexx were assessed $\$ 0.26 /$ steer daily for the last $28 \mathrm{~d}$ of the finishing period. Feedlot yardage was assumed to be $\$ 0.35 /$ steer daily. Interest was charged on feed and yardage costs

\section{Table 1. Premiums and discounts used for grid market analysis $^{1}$}

\begin{tabular}{lc} 
Item & $\begin{array}{c}\text { Premiums and } \\
\text { discounts, } \mathbf{\$} \mathbf{4 5} \mathbf{~ k g}\end{array}$ \\
\hline Prime & 8.00 \\
Upper Choice & 6.00 \\
Choice & 0.00 \\
Select & -8.10 \\
Standard & -15.00 \\
YG 1 & 3.00 \\
YG 2 & 3.00 \\
YG 3 & 0.00 \\
YG 4 & -10.00 \\
YG 5 & -17.49 \\
Carcass wt & -10.00 \\
>432 kg & \\
Carcass wt & -20.00 \\
>455 kg & \\
\hline
\end{tabular}

${ }^{1}$ Grid used for all marketing scenarios.

for half the finishing period. Slaughter breakeven was calculated by dividing the total cost by carcassadjusted final BW.

Profit was calculated in 2 ways. First, profit was calculated using the 7 -yr average live price for the month of December $(\$ 74.23 / 45 \mathrm{~kg})$ and subtracting the total cost of production from the value of the animal. Second, profit was calculated by selling cattle in a value-based beef market that rewards for quality. The grid (Table 1) was calculated using 2 yr of grid prices from the plant where the cattle were sold and averaging the premiums and discounts received for the carcasses. The base for this grid was a carcass with a minimum QG of Choice $^{0}$ and a YG of 3 . The base price was the average Nebraska dressed fed cattle price of YG 3 and Choice $^{0}$ for December (\$121.59/45 kg; Feuz, 2004) from 1998 to 2004. This price was calculated using the Nebraska Dressed Price (1998 to 2004) adjusted by adding the sum of 1 minus the average Choice grading percentage for the month of December multiplied by the Choice-Select spread for the month of December. 
Table 2. Feedlot performance as a main effect of sorting yearling steers by initial feedlot BW

\begin{tabular}{|c|c|c|c|c|}
\hline Item & Sorted & Unsorted & SEM & $P$-value \\
\hline \multicolumn{5}{|l|}{ Feedlot performance } \\
\hline Initial BW, ${ }^{1} \mathrm{~kg}$ & 234 & 236 & 4 & 0.14 \\
\hline $\mathrm{GINT}^{2} \mathrm{~kg}$ & 344 & 345 & 5 & 0.73 \\
\hline $\mathrm{FINT}^{3}{ }^{3} \mathrm{~kg}$ & 436 & 435 & 9 & 0.82 \\
\hline Final BW, kg & 645 & 640 & 2 & 0.15 \\
\hline Winter ADG, kg/d & 0.74 & 0.73 & 0.05 & 0.32 \\
\hline Summer ADG, kg/d & 0.64 & 0.63 & 0.02 & 0.65 \\
\hline Feedlot ADG, kg/d & 1.84 & 1.84 & 0.09 & 0.88 \\
\hline Days on feed & 114 & 111 & - & - \\
\hline DMI, kg/d & 13.12 & 13.04 & 0.08 & 0.35 \\
\hline $\mathrm{G}: \mathrm{F}$ & 0.140 & 0.141 & 0.006 & 0.50 \\
\hline \multicolumn{5}{|l|}{ Carcass characteristic } \\
\hline Carcass wt, kg & 406 & 403 & 1 & 0.14 \\
\hline Fat thickness, cm & 1.27 & 1.12 & 0.10 & 0.02 \\
\hline $\mathrm{LM}$ area, $\mathrm{cm}^{2}$ & 93.61 & 88.39 & 0.77 & $<0.01$ \\
\hline YG & 2.90 & 2.80 & 0.11 & 0.27 \\
\hline Marbling score 4 & 576.6 & 571.6 & 32.2 & 0.35 \\
\hline$\%$ Choice & 80.7 & 79.3 & - & 0.36 \\
\hline$\%$ carcasses $>432 \mathrm{~kg}$ & 14.2 & 15.1 & - & 0.81 \\
\hline$\%$ carcasses $>455 \mathrm{~kg}$ & 1.5 & 3.0 & - & 0.32 \\
\hline$\%$ YG 4+ & 17.0 & 7.6 & - & $<0.01$ \\
\hline
\end{tabular}

${ }^{1}$ Initial BW = BW at the beginning of the production system.

${ }^{2}$ GINT $=$ BW at the beginning of summer grazing.

${ }^{3} \mathrm{FINT}=\mathrm{BW}$ at the beginning of the finishing period.

${ }^{4}$ Marbling score: $400=$ slight $^{0}, 500=$ small $^{0}$, etc.

Statistical Analysis. Performance and economic data were analyzed as a $2 \times 2$ factorial arrangement of treatments using the MIXED procedure (SAS Inst. Inc., Cary, NC). In this study, there were 8 experimental units per year (2 per treatment). Year was used as a random variable, and sort and Optaflexx were fixed effects. In all analyses, pen (group) was the experimental unit. In this experiment, there were no sort $x$ Optaflexx interactions $(P>0.10)$; therefore, the effects of sorting and Optaflexx supplementation on performance and economics are presented as main effects. Even though steers were managed as one group during winter and summer grazing, performance for the winter and summer grazing periods was retrospectively evaluated using the pen (group) assignments at feedlot entry as the experimental unit. Percentage of Choice, percentage of overweight carcasses, and percentage of YG 4 carcasses were analyzed using PROC FREQ (SAS Inst. Inc.) and assuming a binomial distribution. Significance was determined when the probability level was 0.05 or less.

\section{RESULTS AND DISCUSSION}

Treatments were imposed at feedlot entry; therefore, cattle were managed as one group during the winter and summer grazing periods. In yr 1 , steers were wintered for $140 \mathrm{~d}$ and gained $0.78 \mathrm{~kg} / \mathrm{d}$, and in yr 2, steers were wintered for $160 \mathrm{~d}$ and gained $0.69 \mathrm{~kg} / \mathrm{d}$ (Table 2). During the summer grazing period, in yr 1 , steers grazed for $141 \mathrm{~d}$ and gained 0.61 $\mathrm{kg} / \mathrm{d}$, and in yr 2, steers grazed for $146 \mathrm{~d}$ and gained $0.65 \mathrm{~kg} / \mathrm{d}$.

Sorting Feedlot Performance. Initial $\mathrm{BW}$ for the finishing period $(P=0.82$; Table 2$)$ and final BW $(P$ $=0.15)$ were not different; however, sorted cattle were $5 \mathrm{~kg}$ heavier at slaughter compared with unsorted cattle. This is because sorted cattle were fed an average of $3 \mathrm{~d}$ longer than unsorted cattle. Dry matter intake $(P$ $=0.35), \mathrm{ADG}(P=0.88)$, and $\mathrm{G}: \mathrm{F}$ $(P=0.50)$ were not different when sorted cattle were compared with unsorted cattle.

The increase in days fed is consistent with data presented by Folmer et al. (2008), who reported that sorting allowed sorted steers to be fed $6 \mathrm{~d}$ longer than unsorted steers because heavier steers were removed from the pen (group). Similarly, MacDonald et al. (2003) found that sorting allowed for an increase in days on feed of 8 d. By sorting the heavy cattle for market, the lighter cattle could be fed longer, increasing the amount of BW sold without increasing the number of overweight carcasses. Folmer et al. (2008) found that sorting cattle increased final BW by $9 \mathrm{~kg}$. The significant difference in final BW presented by Folmer et al. (2008) and the lack of a significant response to final BW presented in the current study are possibly explained by the sorting technique and the differences in days fed for control and sorted cattle. Folmer et al. (2008) sorted 25\% heavy, $50 \%$ medium, and $25 \%$ light. In the present study, cattle were sorted into groups of $32 \%$ heavy, $44 \%$ medium, and $24 \%$ light. Cattle allotted to lighter BW groups in the previous study were fed longer, resulting in a larger increase in final BW. Sorted cattle were fed $6 \mathrm{~d}$ longer by Folmer et al. (2008) compared with the current study, in which sorted cattle were fed $3 \mathrm{~d}$ longer.

Folmer et al. (2008) used steers that exhibited SD in initial feedlot BW of $32 \mathrm{~kg}$ for both sorted and unsorted steers. In the current study, steers exhibited approximately $10 \mathrm{~kg}$ less variation in feedlot initial BW 
(Table 3). The reduction in variation in feedlot initial BW observed in this study compared with that by Folmer et al. (2008) perhaps explains the difference in sorting response observed in the current study compared with the previous study. However, MacDonald et al. (2006) used steers that exhibited SD of initial BW for unsorted and sorted steers similar to those of Folmer et al. (2008), and they reported no difference in final BW for sorted and unsorted steers. Therefore, variation in feedlot initial BW may not be the explanation for differences in final BW when comparing the study by Folmer et al. (2008) and the current study. In the 2 previous sorting studies (MacDonald et al., 2006; Folmer et al., 2008), pen space per animal and linear bunk space per animal were not held constant; however, in this study cattle were held to a constant pen space and constant bunk space per animal. In the study conducted by MacDonald et al. (2006), steers had $52 \mathrm{~m}^{2}$ /steer before sorting, and after the heavier steers were slaughtered, the remaining steers were allowed $103 \mathrm{~m}^{2} /$ steer. In the study conducted by Folmer et al. (2008), steers in the control pen had the least amount of pen space per steer when compared with the 3 sort groups of $25 \%$ heavy, $50 \%$ medium, and $25 \%$ light steers. The $25 \%$ heavy and the $25 \%$ light steers were allowed $86 \mathrm{~m}^{2}$ pen space/ steer and the $50 \%$ medium steers were allowed $40 \mathrm{~m}^{2}$, with the control steers allowed $21 \mathrm{~m}^{2}$. Mader and Colgan (2007) allowed cattle either 46 or $23 \mathrm{~m}^{2} /$ head and concluded there was no difference in ADG or DMI; therefore, differences in pen space in the previous 2 sorting studies and the current sorting study may not be due to differences in allowed pen space for the sorted and unsorted steers. Similarly, bunk space was not held constant in the studies by MacDonald et al. (2006) and Folmer et al. (2008) for sorted and unsorted cattle, with control cattle having less bunk space than sorted cattle. In the study conducted by MacDonald et al. (2006), linear bunk space for the control cattle was $73 \mathrm{~cm} /$ steer for the entire feeding period; however, within sorted steers when the heavy steers were sold, bunk space for the remaining light steers was $146 \mathrm{~cm} / \mathrm{steer}$. The unsorted cattle in the study conducted by Folmer et al. (2008) had $29 \mathrm{~cm}$ of linear bunk space compared with sorted heavy and light cattle, which had $122 \mathrm{~cm} /$ steer, and sorted medium cattle, which had $55 \mathrm{~cm} /$ steer of linear bunk space, compared with the current study, in which bunk space was held constant at $46 \mathrm{~cm} /$ steer. It is recommended that cattle have 24 to $25 \mathrm{~cm}$ of linear bunk space per animal (Horton, 1990). Additionally, Zinn (1989) reported that bunk

\section{Table 3. Standard deviation of weights and carcass characteristics of sorted and unsorted yearling steers ${ }^{1}$}

\begin{tabular}{lcccc} 
Item & Sorted & Unsorted & SEM & $P$-value \\
\hline FINT, $^{2} \mathrm{~kg}$ & 19.0 & 20.8 & 0.5 & 0.20 \\
Final BW, kg & 35.3 & 45.5 & 0.5 & 0.02 \\
Carcass wt, kg & 22.3 & 28.7 & 0.5 & 0.02 \\
ADG, kg/d & 0.77 & 0.26 & 0.50 & 0.83 \\
Fat thickness, cm & 0.38 & 0.33 & 2.72 & 0.27 \\
LM area, cm ${ }^{2}$ & 7.55 & 7.74 & 7.10 & 0.82 \\
YG & 0.62 & 0.55 & 1.10 & 0.28 \\
Marbling score $^{3}$ & 81.3 & 87.1 & 1.1 & 0.57 \\
\hline
\end{tabular}

${ }^{1}$ Statistical analysis based on log base 10 of SD. Values reported are transformation from log base 10 values.

${ }^{2} \mathrm{FINT}=\mathrm{BW}$ at the beginning of the finishing period.

${ }^{3}$ Marbling score: $400=$ slight $^{0}, 500=$ small $^{0}$, etc. space in excess of $15 \mathrm{~cm} /$ head did not improve feeding performance. In both of the previous sorting studies and in the current sorting study, bunk space exceeded these recommendations; therefore, bunk space is likely not an explanation for the different performance responses to sorting by initial feedlot BW in the 3 studies.

\section{Sorting Carcass Character-} istics. Sorted and unsorted cattle exhibited no difference in $\mathrm{HCW}(P$ $=0.14$; Table 2). Additionally, there was no difference in the percentage of carcasses that were more than $432 \mathrm{~kg}(P=0.81)$. Sorted cattle had increased FT $(0.15 \mathrm{~cm} ; P=0.02)$ and increased LM area $\left(5.22 \mathrm{~cm}^{2} ; P\right.$ $<0.01)$. Yield grade $(P=0.27)$ and marbling score $(P=0.35)$ were not different between sorted and unsorted cattle. However, sorted cattle had 9.4 percentage units more carcasses with YG 4 or greater $(P<0.01)$ compared with unsorted cattle because of the increase in the number of days fed. The increased fat thickness for sorted steers compared with unsorted steers seems high for only a 3 -d difference in days fed. Work presented by Griffin et al. (2007) and by Vieselmeyer et al. (1995) suggests that 12th-rib fat deposition for long yearling steers should be 0.0109 to $0.0111 \mathrm{~cm} / \mathrm{d}$. In the current study, the increase in 12th-rib fat deposition was $0.15 \mathrm{~cm}$ for $3 \mathrm{~d}$, which calculates to a deposition rate of $0.05 \mathrm{~cm} / \mathrm{d}$, and is considerably greater than that reported by Griffin et al. (2007) and Vieselmeyer et al. (1995). Additionally, rates of fat deposition from Griffin et al. (2007) and Vieselmeyer et al. (1995) did not support the magnitude of increase exhibited in the percentage of YG 4 carcasses. However, results from this study are consistent with the results of Bruns and Pritchard (2003), who found that sorting increased the percentage of YG 4 carcasses because of the increase in days fed. However, in the present study the increase in YG 4 carcasses did not lead to an improvement in the number of cattle grading Choice or greater $(P=0.36)$.

The increase in $\mathrm{HCW}$ was not as great as in Folmer et al. (2008), 
who found that sorting significantly increased HCW by $6 \mathrm{~kg}$. MacDonald et al. (2006) found that using a 2-way sort did not increase $\mathrm{HCW}$ when compared with unsorted cattle. This difference between the results of Folmer et al. (2008) and the current study are due to the difference in days fed between the sorted and unsorted cattle. In the study by Folmer et al. (2008), sorted steers were fed for $6 \mathrm{~d}$ longer. However, in the current study sorted steers were fed for only $3 \mathrm{~d}$ longer than unsorted steers. Previous sorting systems used by Folmer et al. (2008) and MacDonald et al. (2006) did not show changes in YG. However, Folmer et al. (2008) did report that sorting decreased the number of overweight carcasses.
Variation Analysis. There was no difference in initial BW variation $(P=0.20$; Table 3$)$. However, sorting did decrease the variation in final BW by $10.2 \mathrm{~kg}(P=0.02)$ because of a $6.4-\mathrm{kg}$ decrease in $\mathrm{HCW}$ variation $(P=0.02)$, which is consistent with the results of Folmer et al. (2008). Additionally, MacDonald et al. (2006) reported a numerical decrease $(P<$ $0.08)$ in SD for final BW of sorted steers compared with unsorted steers. Folmer et al. (2008) used steers that exhibited SD in initial feedlot BW of $32 \mathrm{~kg}$ for both sorted and unsorted steers. In the current study, steers exhibited approximately $10 \mathrm{~kg}$ less variation in feedlot initial BW. Sorting did not affect the variation in ADG $(P=0.83)$. Comparison of the variation in carcass characteristics

\section{Table 4. Feedlot performance as a main effect of supplementing $200 \mathrm{mg}$ of Optaflexx/steer daily to yearling steers for the last $28 \mathrm{~d}$ of the feeding period}

\begin{tabular}{lcccc} 
Item & Optaflexx & Control & SEM & $P$-value \\
\hline Feedlot performance & & & & \\
$\quad$ Initial BW, ${ }^{1} \mathrm{~kg}$ & 235 & 234 & 4 & 0.29 \\
GINT, ${ }^{2} \mathrm{~kg}$ & 344 & 345 & 5 & 0.89 \\
FINT, ${ }^{3} \mathrm{~kg}$ & 436 & 435 & 9 & 0.82 \\
Final BW, kg & 643 & 642 & 2 & 0.86 \\
& & & & \\
Winter ADG, kg/d & 0.73 & 0.74 & 0.05 & 0.32 \\
Summer ADG, kg/d & 0.64 & 0.63 & 0.02 & 0.72 \\
Feedlot ADG, kg/d & 1.85 & 1.84 & 0.09 & 0.85 \\
& & & & \\
Days on feed & 113 & 113 & - & - \\
DMI, kg/d & 13.09 & 13.07 & 0.08 & 0.75 \\
G:F & 0.141 & 0.140 & 0.006 & 0.82 \\
& & & & \\
Carcass characteristic & & & & \\
Carcass wt, kg & 405 & 405 & 1 & 0.83 \\
Fat thickness, cm & 1.19 & 1.19 & 0.10 & 0.72 \\
LM area, cm ${ }^{2}$ & 91.03 & 90.97 & 0.77 & 0.95 \\
YG & 2.84 & 2.86 & 0.11 & 0.77 \\
Marbling score & 573.5 & 574.8 & 32.2 & 0.81 \\
& & & & \\
\% Choice & 80.2 & 79.8 & - & 0.79 \\
\% carcasses $>432 \mathrm{~kg}$ & 17.2 & 12.1 & - & 0.16 \\
\% carcasses $>455 \mathrm{~kg}$ & 2.5 & 2.0 & - & 0.74 \\
\% YG 4+ & 11.9 & 12.6 & - & 0.82 \\
\hline
\end{tabular}

${ }^{1}$ Initial BW = BW at the beginning of the production system.

${ }^{2} \mathrm{GINT}=\mathrm{BW}$ at the beginning of summer grazing.

${ }^{3} \mathrm{FINT}=\mathrm{BW}$ at the beginning of the finishing period. of sorted cattle and unsorted cattle showed no difference in LM area $(P$ $=0.82), \mathrm{FT}(P=0.27), \mathrm{YG}(P=$ $0.28)$, and marbling score $(P=0.57)$. However, Folmer et al. (2008) found that sorting by initial BW increased the variation in marbling score $(63.3$ vs. 41.3 ; marbling score: $400=$ slight $^{0}$, $500=$ small $\left.^{0}\right)$.

Optaflexx Feedlot Performance. Diets were formulated to provide $14.69 \mathrm{~g}$ Optaflexx/metric ton of feed, which is equivalent to $200 \mathrm{mg}$ Optaflexx/steer daily, assuming steers consumed $13.64 \mathrm{~kg}$ of $\mathrm{DM} / \mathrm{d}$. In this study, DM consumption was 13.09 $\mathrm{kg} / \mathrm{d}$, which led to an Optaflexx consumption of $192.2 \mathrm{mg} /$ steer daily.

There was no difference in feedlot initial BW of Optaflexx-supplemented cattle compared with cattle not supplemented with Optaflexx $(P=$ 0.82; Table 4). Supplementing Optaflexx for the last $28 \mathrm{~d}$ of the feeding period did not affect final BW $(P$ $=0.86), \operatorname{ADG}(P=0.85), \mathrm{G}: \mathrm{F}(P$ $=0.82)$, or DMI $(P=0.75)$. These results were somewhat unexpected because previous Optaflexx research has shown increased final BW ranging from 4.1 (Crawford et al., 2006) to 7.7 $\mathrm{kg}$ (Schroeder et al., 2003) for cattle supplemented with $200 \mathrm{mg}$ Optaflexx/ steer daily. Cattle supplemented with Optaflexx have also exhibited improvements in G:F (Schroeder et al., 2003; Laudert et al., 2004; Crawford et al., 2006; Greenquist et al., 2007). Schroeder et al. (2003) reported an improvement in performance for cattle fed Optaflexx when cattle were fed an average of $167 \mathrm{~d}$ (range $=136$ to 235 d). Laudert et al. (2004) also reported an improvement in steer feedlot performance when Optaflexx was fed for the last 28 to $32 \mathrm{~d}$ of the feeding period; however, cattle in this study were fed an average of $156 \mathrm{~d}$ (range $=122$ to $180 \mathrm{~d}$ ). Additionally, HCW reported by Laudert et al. (2004) averaged $371 \mathrm{~kg}$. In the current study, cattle were fed for $113 \mathrm{~d}$ and had HCW that averaged $405 \mathrm{~kg}$. When compared with the current study, the steers represented by Schroeder et al. (2003) and Laudert et al. (2004) required more days fed and had lighter HCW. 
Table 5. Economic analysis as a main effect of sorting yearling steers by initial feedlot weight

\begin{tabular}{|c|c|c|c|c|}
\hline Item & Sorted & Unsorted & SEM & $P$-value \\
\hline Steer cost, \$/steer & 530.66 & 538.70 & 8.25 & 0.08 \\
\hline Interest, ${ }^{1}$ \$/steer & 64.16 & 64.04 & 3.38 & 0.60 \\
\hline Feed cost, \$/steer & 162.73 & 158.47 & 1.25 & $<0.01$ \\
\hline Yardage, \$/steer & 39.88 & 38.85 & 0.09 & $<0.01$ \\
\hline Total cost, $\$$ /steer & $1,018.54$ & $1,008.05$ & 20.93 & 0.78 \\
\hline System COG, ${ }^{2} \$ / 45 \mathrm{~kg}$ & 44.98 & 45.50 & 1.18 & 0.28 \\
\hline Feedlot $\mathrm{COG},{ }^{3} \$ / 45 \mathrm{~kg}$ & 46.47 & 46.22 & 2.36 & 0.30 \\
\hline Breakeven, $\$ / 45$ kg & 71.60 & 72.04 & 1.56 & 0.31 \\
\hline Live value, ${ }^{4} \$$ /steer & $1,053.57$ & $1,046.45$ & 3.25 & 0.15 \\
\hline Grid value, ${ }^{5} \$ /$ steer & $1,061.54$ & $1,057.32$ & 10.67 & 0.55 \\
\hline Live $p / l,{ }^{6} \$ /$ steer & 39.80 & 33.63 & 21.72 & 0.29 \\
\hline Grid p/l, ${ }^{6} \$ /$ steer & 51.82 & 48.55 & 31.07 & 0.68 \\
\hline \multicolumn{5}{|c|}{$\begin{array}{l}{ }^{1} \text { Interest is the total amount of interest accrued from the animal and all cost of } \\
\text { production. }\end{array}$} \\
\hline \multicolumn{5}{|c|}{${ }^{2}$ System COG is the cost of gain for the entire production system. } \\
\hline \multicolumn{5}{|c|}{${ }^{3}$ Feedlot COG is the cost of gain during the finishing period. } \\
\hline \multicolumn{5}{|c|}{${ }^{4}$ Live sale price of $\$ 74.23 / 45 \mathrm{~kg}$. } \\
\hline \multicolumn{5}{|c|}{${ }^{5}$ Carcass base price of $\$ 121.59 / 45 \mathrm{~kg}$. } \\
\hline${ }^{6} \mathrm{p} / \mathrm{l}=$ profit or loss. & & & & \\
\hline
\end{tabular}

Differences between the current study and those by Schroeder et al. (2003) and Laudert et al. (2004) suggest that a different type of cattle was used. In studies conducted by Quinn et al. (2008) and Winterholler et al. (2008), cattle entered the feedlot with initial BW of 471 and $400 \mathrm{~kg}$, respectively. Additionally, cattle used by Quinn et al. (2008) and Winterholler et al. (2008) were fed for 103 and $123 \mathrm{~d}$, respectively. These cattle are similar in type compared with the cattle used in the current study. In the studies of both Quinn et al. (2008) and Winterholler et al. (2008), no difference was found in final BW for cattle supplemented with Optaflexx compared with cattle not supplemented with Optaflexx. However, both Quinn et al. (2008) and Winterholler et al. (2008) reported an improvement in G:F when Optaflexx was supplemented.

Optaflexx Carcass Characteristics. Feeding Optaflexx had no impact on $\mathrm{HCW}(P=0.83)$, FT $(P$ $=0.72), \mathrm{LM}$ area $(P=0.95), \mathrm{YG}(P$
$=0.77)$, or marbling score $(P=0.81$ Table 4). There was not a difference in the percentage of cattle with carcasses heavier than $432 \mathrm{~kg}(P=0.16)$.
With the exception of HCW, previous research has shown variable results in FT, YG, and LM area. Crawford et al. (2006) and Schroeder et al. (2003) reported that Optaflexx supplementation had no effect on FT. Optaflexx has been shown to increase LM area (Schroeder et al., 2003; Crawford et al., 2006; Greenquist et al., 2007) and improve YG (Schroeder et al., 2003; Greenquist et al., 2007). Additionally, Quinn et al. (2008) reported no difference in carcass characteristics for cattle supplemented with Optaflexx compared with cattle not supplemented with Optaflexx. Similarly, Winterholler et al. (2008) reported a decrease in marbling score and an improvement in YG; however, other carcass measures were similar for cattle supplemented with Optaflexx compared with cattle not supplemented with Optaflexx.

Sorting Economics. Unsorted cattle had a numerically greater initial animal cost of $\$ 8.04$ /steer $(P=0.08)$ compared with sorted cattle (Table 5). The increase in initial animal cost was due to the unsorted cattle being numerically $2 \mathrm{~kg}$ heavier $(P=0.14)$ than sorted cattle upon entering the system. Because cattle were managed as one group during the winter and summer grazing periods, costs of
Table 6. Effect of sorting by initial feedlot BW on percentage of overweight carcasses, percentage of YG 4 carcasses, percentage of choice carcasses, and profitability

\begin{tabular}{|c|c|c|c|}
\hline Item $^{1}$ & MacDonald et al. (2006) & Folmer et al. (2008) & Current Study \\
\hline FINT SD:FINT ${ }^{2}$ & 0.07 & 0.07 & 0.05 \\
\hline Days fed & $8^{3}$ & 6 & 3 \\
\hline $\begin{array}{l}\% \text { carcasses }>432 \\
\mathrm{~kg}^{4}\end{array}$ & -3.0 & -8.1 & -0.9 \\
\hline$\%$ YG $4+^{4}$ & - & -0.4 & 9.4 \\
\hline$\%$ Choice $^{4}$ & - & 0.8 & 1.4 \\
\hline Live $p / l,{ }^{5} \$ /$ steer & 0.88 & 2.62 & 6.17 \\
\hline Grid p/l, ${ }^{5} \$ /$ steer & 8.21 & 16.51 & 3.27 \\
\hline
\end{tabular}

${ }^{1}$ Data presented as difference between sorted and unsorted steers.

${ }^{2}$ FINT = feedlot initial BW; FINT SD:FINT = SD of feedlot initial BW to feedlot initial BW ratio.

${ }^{3}$ Reported in MacDonald et al. (2003).

${ }^{4}$ Data are presented as percentage unit differences.

${ }^{5} \mathrm{p} / \mathrm{l}=$ profit or loss. 


\begin{tabular}{|c|c|c|c|c|}
\hline Item & Optaflexx ${ }^{1}$ & Control & SEM & $P$-value \\
\hline Steer cost, $\$ /$ steer & 537.95 & 531.41 & 8.25 & 0.14 \\
\hline Interest, ${ }^{2} \$ /$ steer & 64.22 & 63.97 & 3.38 & 0.29 \\
\hline Feed cost, \$/steer & 160.71 & 160.50 & 1.25 & 0.82 \\
\hline Yardage, \$/steer & 39.37 & 39.37 & 0.09 & 1.00 \\
\hline Total cost, \$/steer & $1,018.54$ & $1,008.05$ & 20.93 & $<0.01$ \\
\hline System COG, ${ }^{3} \$ / 45 \mathrm{~kg}$ & 45.53 & 44.95 & 1.18 & 0.23 \\
\hline Feedlot COG,${ }^{4} \$ / 45 \mathrm{~kg}$ & 47.29 & 45.40 & 2.36 & 0.01 \\
\hline Breakeven, $\$ / 45 \mathrm{~kg}$ & 72.18 & 71.46 & 1.56 & 0.10 \\
\hline Live value, ${ }^{5} \$ /$ steer & $1,050.45$ & $1,049.58$ & 3.25 & 0.85 \\
\hline Grid value, ${ }^{6} \$ /$ steer & $1,057.15$ & $1,061.17$ & 10.67 & 0.52 \\
\hline Live $\mathrm{p} / \mathrm{l}, 7$ \$steer & 31.90 & 41.53 & 21.72 & 0.11 \\
\hline Grid p/l, $\$ /$ steer & 42.64 & 57.72 & 31.07 & 0.08 \\
\hline
\end{tabular}

${ }^{1}$ Optaflexx was charged at a rate of $\$ 0.26 /$ head daily in the last $28 \mathrm{~d}$ of the feeding period.

${ }^{2}$ Interest is the total amount of interest accrued from the animal and all costs of production.

${ }^{3}$ System COG is the cost of gain for the entire production system.

${ }^{4}$ Feedlot COG is the cost of gain during the finishing period.

${ }^{5}$ Live sale price of $\$ 74.23 / 45 \mathrm{~kg}$.

${ }^{6}$ Carcass base price of $\$ 121.59 / 45 \mathrm{~kg}$.

${ }^{7} \mathrm{p} / \mathrm{l}=$ profit or loss. by initial feedlot BW did not result in significant differences in breakeven costs, live profitability, or marketing grid profitability. However, studies by MacDonald et al. (2006) and Folmer et al. (2008) and the current study show that sorting cattle increases profitability numerically on both a live and grid basis (Table 6 ). In all 3 studies, sorted cattle were numerically more profitable than unsorted control cattle; however, statistical differences in the economic performance could not be detected because of variations in the biological performance, and the power of these studies may not have been great enough to statistically differentiate small differences in profitability (Kononoff and Hanford, 2006). In production agriculture, the increase in profit exhibited by sorted steers in each of these studies would be considerable because live profit increases ranged from $\$ 0.88$ to $\$ 6.17 /$ steer and grid profit increases ranged from $\$ 3.31$ to $\$ 16.51 /$ steer. Additionally, Feuz (2002) found that increasing the days fed by 2 wk was more profitable during the finishing phase because of increased BW and increased QG. However, in the present study, increasing days fed by sorting produced more YG 4 carcasses and no differences in $\mathrm{QG}$, offsetting the additional income received from the slight increase in final BW.

Optaflexx Economics. The initial animal cost was numerically higher for cattle supplemented with Optaflexx $(P=0.14$; Table 7$)$. There was no difference in feedlot yardage cost $(P=1.00)$ or feed cost $(P=0.82)$. The interest cost $(P=0.29)$ was not different when cattle supplemented with Optaflexx were compared with control cattle. However, the total cost of production $(P<0.01)$ was $\$ 10.49$ higher for cattle supplemented with Optaflexx. The increase in total cost was due to the slight increase in the initial animal cost and the price of supplementing Optaflexx ( $\$ 0.26 /$ steer daily).

The cost of supplementing Optaflexx led to a slight increase in the breakeven cost of $\$ 0.72 /$ cwt $(P=$ $0.10)$; however, no difference was valuable on a live basis $(P=0.15)$ in $\mathrm{HCW}$. However, the increase in in increased profitability of sorted cattle $(P=0.29)$. When sorted and unsorted cattle were compared using different $(P=0.55)$ because of the increase in the number of discount with YG 4 and because sorting did not reduce the number of carcasses receiving overweight discounts. Because the animal value was not increased for sorted cattle, the profitability of sorted cattle was not different $(P=$ $0.68)$ from that of unsorted cattle.

The economic results in the present study are consistent with those of MacDonald et al. (2006) and Folmer et al. (2008), who found that sorting
When comparing the final animal value, sorted cattle were $\$ 7.12$ more 
observed in the system cost of BW gain $(P=0.23)$ even though Optaflexx increased feedlot cost of BW gain of $\$ 1.89(P=0.01)$. The final animal value on a live $(P=0.85)$ or grid marketing $(P=0.52)$ basis was not different. However, when live profitability and grid profitability were compared, Optaflexx-supplemented cattle tended to be $\$ 9.63(P=0.11)$ and $\$ 15.08(P=0.08)$ less profitable, respectively, than control cattle. The decrease in profitability was due to the increased cost of supplementing Optaflexx and no performance benefit, and because cattle supplemented with Optaflexx tended to produce more overweight carcasses. The lack of a response to Optaflexx feeding was unexpected based on the responses seen in previous Optaflexx trials (Schroeder et al., 2003; Crawford et al., 2006; Greenquist et al., 2007); however, because of the lack of a response to feeding Optaflexx, profitability on both a live and a grid basis tended to be less for cattle supplemented with Optaflexx.

\section{IMPLICATIONS}

In this study, sorting cattle by initial feedlot BW was not successful because the final BW and the percentage of overweight carcasses were not reduced and the incidence of $\mathrm{YG}$ 4 carcasses increased. Sorting statistically increased LM area for sorted cattle compared with unsorted cattle. However, there was no economic advantage for sorted cattle. Feeding Optaflexx to long yearlings had no impact on performance. Economic analysis in this study suggests that feeding Optaflexx does not improve the profitability of long yearlings.

\section{LITERATURE CITED}

Boggs, D. L., and R. A. Merkel. 1993. Beef carcass evaluation, grading, and pricing. p. 105 in D. L. Boggs and R. A. Merkel, ed. Live Animal Carcass Evaluation and Selection Manual. Kendel/Hunt Publishing Co., Dubuque, IA.

Bruns, K. W. and R. H. Pritchard. 2003. Sorting cattle - A review. South Dakota Beef Rep. BEEF2003-10:60.
Crawford, G. I., G. E. Erickson, K. J. Vander Pol, M. A. Greenquist, J. D. Folmer, and M. T. Van Koevering. 2006. Effect of Optaflexx dosage and duration of feeding prior to slaughter on feed conversion and carcass characteristics. Nebraska Beef Rep. MP 88-A:2.

Dolezal, H. G., J. D. Tatum, and F. L. Williams Jr. 1993. Effects of feeder cattle frame size, muscle thickness, and age class on days fed, weight, and carcass composition. J. Anim. Sci. 71:2975.

Erickson, G. E., T. J. Klopfenstein, K. J. Vander Pol, V. R. Bremer, and P. L. Loza. 2005. Feeding wet corn milling byproducts to beef cattle. p. 69 in Proc. 66th Minnesota Nutrition Conference, St. Paul. Univ. Minnesota, St. Paul.

Feuz, D. M. 2002. A simulated market analysis of altering days on feed and marketing cattle on specific value-based pricing grids. Nebraska Beef Rep. MP 79-A:39.

Feuz, D. M. 2004. Feuz market analysis. http://cattlemarketanalysis.org/ Accessed Jan. 4, 2006.

Folmer, J. D., W. A. Griffin, C. N. Macken, M. P. Blackford, T. J. Klopfenstein, and G. E. Erickson. 2008. Effect of intensive winter management, partial season grazing, and sorting on performance and economics of a long yearling steer production system. Prof. Anim. Sci. 24:411.

Greenquist, M. A., K. J. Vander Pol, G. E. Erickson, T. J. Klopfenstein, W. J. Platter, and M. T. Van Koevering. 2007. Performance profile and carcass characteristics of steers fed Optaflexx. Nebraska Beef Rep. MP 90:65.

Griffin, W. A., T. J. Klopfenstein, G. E. Erickson, D. M. Feuz, J. C. MacDonald, and D. J. Jordon. 2007. Comparison of performance and economics of a long-yearling and calf-fed system. Prof. Anim. Sci. 23:490.

Horton, J. M. 1990. Bunk management, feed delivery, and water trough management. p. 137 in Cattle Feeding: A Guide to Management. R. C. Albin and G. B. Thompson, ed. Trafton Printing Inc., Amarillo, TX.

Johnson, B., and A. Raymond. 1993-2005. Nebraksa farmland values. Husker Economics. Univ. Nebraka Ext. Publ. Univ. Nebraska, Lincoln.

Jordon, D. J. 2000. Perfomance and slaughter breakeven analysis of calf and yearling systems and compensatory growth. PhD Diss. Univ. Nebraska, Lincoln.

Kleiber, M. 1975. The Fire of Life: An Introduction to Animal Entergetics. R. E. Kreiger, New York, NY.

Kononoff, P. J., and K. J. Hanford. 2006. Technical note: Estimating statistical power of mixed models used in dairy nutrition experiments. J. Dairy Sci. 89:3968.

Kuehl, R. O. 2000. Power transformations to stabilize variances. p. 135 in Design of Experiments: Statistical Principles of Research
Design and Analysis. C. Crockett and C. Dowcett, ed. Brooks Cole Publishing Co., Grove, CA.

Laudert, S. B., G. J. Vogel, W. J. Platter, and M. T. Van Koevering. 2004. The effect of Optaflexx on growth performance and carcass traits of steers: Summary of six post-registration studies. Optaflexx Exchange: Scientific Update No. 4. Elanco Animal Health, Greenfield, IN.

MacDonald, J. C., T. J. Klopfenstein, G. E. Erickson, C. N. Macken, J. D. Folmer, and M. P. Blackford. 2003. Sorting strategies for yearlings. Nebraska Beef Rep. MP 80-A:65.

MacDonald, J. C., T. J. Klopfenstein, G. E. Erickson, C. N. Macken, J. D. Folmer, and M. P. Blackford. 2006. Sorting strategies for long yearling cattle grown in an extensive forage utilization beef production system. Prof. Anim. Sci. 22:225.

MacDonald, J. C., T. J. Klopfenstein, C. N. Macken, J. D. Folmer, M. P. Blackford, and D. J. Jordon. 2002. Sorting strategies in an extensive forage utilization beef production system. Nebraska Beef Rep. MP 79-A:36.

Mader, T. L., and S. L. Colgan. 2007. Pen density and straw bedding during feedlot finishing. Nebraska Beef Rep. MP 90:43.

Mersmann, H. J. 1998. Overview of the effects of $\beta$-adrenergic receptor agonists on animal growth including mechanism of action. J. Anim. Sci. 76:160

Meyer, T. L., D. C. Adams, T. J. Klopfenstein, J. D. Volesky, L. A. Stalker, and R. N. Funston. 2008. Estimating livestock forage demands: Defining the animal unit (AU). Proc. 2008 Am. Soc. Anim. Sci. Western Sect. Mtg. 59:213.

Owens, F. N., P. Dubeski, and C. F. Hanson. 1993. Factors that alter the growth and development of rumnants. J. Anim. Sci. 71:3138.

Quinn, M. J., C. D. Reinhardt, E. R. Loe, B. E. Depenbusch, M. E. Corrigan, M. L. May, and J. S. Drouillard, 2008. The effects of ractopamine-hydrogen chloride (Optflexx) on performance, carcass characteristics, and meat quality of finishing feedlot heifers. J. Anim. Sci. 86:902.

Schroeder, A. L., D. M. Polser, S. B. Laudert, and G. J. Vogel. 2003. The effect of Optaflexx on growth performance and carcass traits of steers: Five-trial registration summary. Optaflexx Exchange: Scientific Update No. 1. Elanco Animal Health, Greenfield, IN.

Shain, D. H., T. J. Klopfenstein, R. A. Stock, B. A. Vieselmeyer, and G. E. Erickson. 2005. Evaluation of grazing alternate summer and fall forages in extensive beef cattle production systems. Prof. Anim. Sci. 21:390.

Stock, R., T. Klopfenstein, D. Brink, S. Lowery, D. Rock, and S. Abrams. 1983. Impact of weighing procedures and variation in protein degradation rate on measured performance 
of growing lambs and cattle. J. Anim. Sci. $57: 1276$.

during finishing. Nebraska Beef Rep. MP 62-A:46.

Vieselmeyer, B., T. Klopfenstein, R. Stock, R. Clark, R. Rasby, and D. Shain. 1995. Physiological and economic changes of beef cattle
Winterholler, S. J., G. L. Parsons, D. K.

Walker, M. J. Quinn, J. S. Drouillard, and B. J. Johnson. 2008. Effect of feedlot manage- ment system on response to ractopamine- $\mathrm{HCl}$ in yearling steers. J. Anim. Sci. 86:2401.

Zinn, R. A. 1989. Manger space requirements for limit-fed steers. J. Anim. Sci. 67:853. 